\title{
AN EXPLORATORY STUDY ON DESIGN PROCESS IN ARCHITECTURE: PERSPECTIVE OF CREATIVITY
}

\author{
Shanta Pragyan DASH (D) \\ Manipal School of Architecture and Planning, \\ Academic Block 2, MIT Campus, Manipal 576014, Karnataka, India
}

Received 17 June 2020; accepted 18 June 2021

\begin{abstract}
Any design challenge could be solved by identifying systemic complexity in the issue before following any problem-solving process. Designers approach problems in different forms but historically worked effectively to build a template or phase sequence. The design process can be used by designers virtually in any project which plays a crucial role in designing innovative architectural projects for many architects. Many studies were conducted to analyze, review, compare and recommend several creative approaches to problem management that allow designers to recognize their work and propose new solutions. However, there are not many studies on the stages to follow to undergo a comprehensive design process in architecture. This study aims to review the various stages involved in the design process. Firstly, it addresses the conceptualization phase of design critically examining the creativity and ideation process with creative and strategic thinking. Secondly, it discusses the representation of the design process expressing through storyboards and animatic, computer-aided design and building information modeling, and virtual reality and augmented environments. Thirdly, it discusses design assessment stage where the techniques for assessment of creativity in design and simulation for analyzing users' perspective is explained. In the conclusions of the paper, a discussion has been made on an inter-relationship between the various stages in the design process and its relevance for a comprehensive understanding of the architectural integrative design process to address any design challenge both as a studio project for architecture students or in live projects by the practicing architects.
\end{abstract}

Keywords: architectural design, creativity, innovation, integrative design process, strategic thinking.

\section{Introduction}

Design is defined as an integrated process that has been interlinked with various intermediate representations of a wide range of architectural detailing (S. A. Kim \& Y. S. Kim, 2007). It is mostly defined as an integrated process that involves the creation and utilization of the thought process generated through various cognitive and physical activities related to the design challenge (Abdellatif Abo Wardah \& Khalil, 2016). It has been documented during the mid-1970s and 1980s the major shift in the world of design research has been evident

*Corresponding author. E-mails: shanta.dash@manipal.edu; dashshanta5@gmail.com

Copyright (c) 2021 The Author(s). Published by Vilnius Gediminas Technical University

This is an Open Access article distributed under the terms of the Creative Commons Attribution License (http://creativecommons. $\mathrm{org} / \mathrm{licenses} / \mathrm{by} / 4.0 /$ ), which permits unrestricted use, distribution, and reproduction in any medium, provided the original author and source are credited. 
for achieving the "design discipline" (S. A. Kim \& Y. S. Kim, 2007). During this period, there has been intense documentation of the literature on the methodologies of design which has contributed to major publications during this phase. It has also been in analyzed that it these papers have proposed various methods of the design process comprehensively to enable the designers to explore their ideas and creativity into the design through these design process (Siddique et al., 1990). But at the same time, it was also so evident that there was no unique method of following any design process to achieve a suitable design solution. Several designers have proposed several definitions of the design process in their interpretation based on their experience and challenges they have faced but still, they failed to define the most rational model which is termed as "mystical" phenomenon of the design process (Editorial Board of International Journal of Design Creativity and Innovation, 2013). The main reason behind this was primarily architecture is defined as the most challenging assessment when it comes to assessing creativity. Therefore, the study has been derived from the idea that every architect has his way of defining the concept of design and sets his limitations to achieve functional objectives. Chicago Architecture Centre, United States (Discoverdesign, 2012-2019) has proposed an architectural phenomenon of design which defines the design process as an integrated process comprising smaller chunks within which the entire concept of design has been split down (Figure 1). Primarily, it includes the identification of the problem (the solution of which cannot be addressed unless we need to have a clear understanding about the problem); secondly, the collection of the information (through drawing sketches photographs in order to capture the evidence to initiate the process of design); thirdly, brainstorming and analyzing the ideas (where the designer starts to draw create and research to explore the understanding of how the information gathered can be utilized into resolving the design challenge); fourthly, developing the solutions (which includes the preliminary ideas and the several small-scale design solutions practiced by the designer with various iterations); fifthly, gathering feedback (which includes the feedback of the client for whom the design has been proposed along with the various stakeholders and experts whom the designer seeks to have an insightful comment in order to improvise his design); finally, the improvement stage (which reflects all the feedback from the stakeholders and the client pertaining to the extent to which it could be incorporated to the maximum possible way). The process is the vicious circle where each component is linked to the other to complete the process in a holistic way proposing the desired solution (Kuloglu \& Durmus, 2013).

The architectural design process is also defined as a systematic analysis of the concept ideas and propose design solutions prioritizing the aspects of challenges it has been addressed (Ciepłucha, 2018). According to the researcher, the major challenge in the design process is to capture the major sources of information to the extent of data collection and how eventually the transformation of this information has been implemented in the design solution. There have been numerous studies that have recognized the failure of the traditional design process addressing any design challenge both in the practice and in the studio (Babangida Idi \& bin Mohamed Khaidzir, 2015). Few researchers have found that the design challenges are too complex in today's scenario to address through the traditional approach and therefore has been mostly criticized (Cross, 2001). It has also been found that there has been a lack of objective knowledge which ultimately lacks the new interest of a better quality 
design addressing the design solution (Cross, 2007). However, the design has been always identified as the result of the integrated thinking or as an approach of the integrated response of systems but no design theory exist which can explicitly elaborate on the mechanism of the development of knowledge and integration within the process of design which the study termed as the "design knowledge mechanism". Therefore, the traditional approach of the design process fails to operate systematically, even though there have been various tools to explore the design process, both the researchers and the designers are still trying to explore an environment where the design process is represented in a more insightful and meaningful way (Bashier, 2017). To manage the complex cities of design challenges it is necessary to have a better knowledge of the design process, to improve the design solution through collaboration with various stakeholders and the design team to improve the tool support for the design and to improve the design education in studios as well (Jagtap, 2019).

The paper aims to focus on the comprehensive review of the design process in architecture showing light on the three major phases of the design process. Firstly, it explains the conceptualization stage of the design process, which include the ideation and creativity with a model-based thinking approach, addressing idealizing solution and the visual representation of the various activities or methods followed during the process, design concept generation stage with the analysis and learning from the conceptual design process. Secondly, it discusses the representation stage of the design process which is expressed through storyboards and animatic, and the use of computer-aided design (CAD) and building information modeling (BIM) as a tool of representation followed by virtual reality and the immersive digital interactive and augmented environment to experience the space virtually by the users. Finally, it discusses the assessment stage of the design process addressing the assessment of creativity and innovation followed by a design solution or hypothesis, considering the views of the users and other stakeholders' feedbacks and applying design quality indicator tools for analyzing users' perspective and finally the detailed design phase of the simulation. This research started from the necessity to visualize the design process more intuitively so that one can get an insight into the complicated aspects of the design process, being able to examine

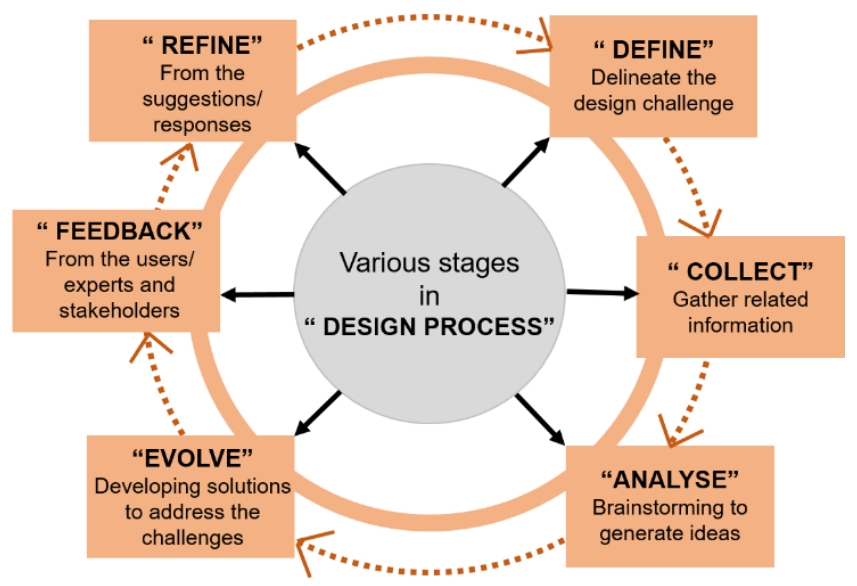

Figure 1. Mapping of design process (source: created by author) 
the dynamic relations among design activities and associated information. The study seeks to contribute to a disciplinary approach through a conceptual framework of various stages of the design process which shall enable the designers to develop a proper understanding of design knowledge mechanisms involved within the design process system.

\section{Conceptualization of design process}

\subsection{Ideation and creativity}

The proposals developed by the designers primarily comprise drawings, writings, and verbal expressions. An artist develops his ideations of abstracts through sketches which are a mode of visual representation enabling him to formulate his creativity. He uses the tools such as visual graphics and representation techniques to express his philosophical ideation transforming it into reality. Therefore, for an artist to ideate his imagination, intellectual imaging is a technique that has been developed and analyzed to portray the thought process. Mental imaging is always regarded as the most effective brainstorming method of putting forth the ideation in a design process (Pryshchenko, 2021). It has also been proved through research that the human mind always tends to use oral and visual processes to balance each other. Most artists use visual imagery to depict various forms and images and modulate them accordingly. Researches have also proved that the mental skills studies indicated that low creative potential has been proved to be more creative than the environment with high creative potential in the field of design (Daniel, 2021). More innovative ideas were generated through image stimuli in comparison to the word or combined stimuli adopted by the designers. For any successful generation of the thought process of a design, sketching skills are the cognitive tools that help the designer to develop their fluency in design. in an early concept, the idea is introduced as an important architectural design embodiment (Taura \& Nagai, 2017). To contribute towards the development of the design world as a fundamental framework of harmonizing and sustaining design effectively, designers use their innovative abilities with the current environmental characteristics (Babangida Idi \& bin Mohamed Khaidzir, 2015). Keeping these architectural characteristics into consideration, for the students who had innovative training in the former study at school and the real situation in our traditional frontal teaching model, it is important to discuss the improvement and the measurement of their creative thought process in architectural education apart from the design activities planned for them. Mostly they are portrayed as analysis, synthesis, and evaluation, seeing-movingseeing, and imaging-presenting-testing techniques (Bashier, 2017). The concept is being synthesized and the objectives with the targets are generated through primary investigations. These created objective and concepts are required to be assessed to improvise it and use it as a design solution. Instead of taking it after a consecutive stage, these exercises are worked out iteratively. Design is an iterative process where the various schemes are identified, investigated, re-examined and continuous improvement is workout until an arrangement is recognized as a final output (Mahmoodi, 2001). This iterative or cyclic process puts on more effort distinctively amid the conceptual plan and it is the phase having abundance inclusions of ideas thoughts imaginations and challenges. Protocol analysis has been broadly implemented as a technique to assess the activities and discover the most important designs from verbal 
convention information. This verbal convention, although not adequate to clarify what is going on amid the plan, in most of the cases. Therefore, sketching is the fundamental technique for creating and narrating the arrangement, conjointly for identify any conflicts and conceivable outcomes. Many studies have been carried out to understand how the designer thinks and pursue their analysis from their sketches. Sketches give a critical clue to get an understanding of the designers' consideration in the evolution process of design (Aroztegui et al., 2010). The trailed plan activities and external presentations when combined, enable us to have a smarter strategy to apply in the phase of ideation and creativity of the design process. Although architectural education must depend on developing a curriculum that should incorporate creative personality, the traditional architectural academic organizations are primarily focused on professional knowledge and skills. Although creativity is the major objective of the design studio, there has not been any course known such as creativity studies in the curriculum of architectural education so far to enhance the aspects of ideation and creativity skills from a design perspective (Ayyýldýz Potur \& Barkul, 2006).

\subsection{Strategic thinking as an initial thinking approach}

Strategic thinking has been defined as the major aspect responsible for intuitive, visual, and simultaneous thinking during the design process which has been defined as the process of generating knowledge that is mainly responsible for idealizing a solution for any design challenge (Abdellatif Abo Wardah \& Khalil, 2016). The three attributes comprising of strategic thinking are primarily synthesizing, where the designer needs to implement the different design possibilities to generate solutions and apply certain design strategies to exercise their design ideas, secondly, elaborating stage where the designer needs to explore and expand their ideas and modify them as well along with the newly generated ideas to enable them to shift their perspective and viewpoints and not restricting their imagination to only one rigid solution and, thirdly, the imagining stage where the designers need to develop fluent responses to predict the final output or the design solution to visualize and speculate the solutions based on their understanding of their fundamental judgments and logistics design decisions (Gohardani, 2011). This strategic thinking phase is the initial thinking approach that can be interlinked with integrated thinking methodology where the design challenges are modeled during the design process and resolved with strong reasoning and justifying the rationale behind it. The fundamental thought approach can be represented as an integral thinking methodology.

\subsection{Model-based design thinking approach}

The design process in architecture, material engineering, and model making play a significant role in demonstrating conceptual ideas. These concepts of design are fundamentally applied as a learning tool to explore the materials' structural, visual and observable properties. This aspect of design thinking was discussed by Le Corbusier in his Ronchamp chapel, Ronchamp, France, where he has worked out on rationalized design solutions with wire models to explain the relationship between the mathematical and physical representation of the geometry (Cross, 2007). Likewise, other architects like Antoni Gaudí, Heinz Isler, and Frei Otto also have explored physical models to explain their concept through parametric, structural 
aspects and complex design solutions. This approach of the demonstration had proved a significant role in building the knowledge expertise and the perspective of design solutions and its execution on the site. Models in the design process are mostly representational devices to demonstrate one's concept even though making full-scale models with prototypes is a time-consuming, tedious, and costly way to explore the complexities between material and structures for many designers. In today's scenario, modern material-based digital production architecture along with the growth in advances in the material science domain has proved to have a significant impact on the architectural thinking process towards digital tectonics (Mahmoud et al., 2020). "Digital turning" in architecture gives the flexibility in developing the model of any form being abstract or regular, enables the designer to portray his imagination into a physical model without compromising on the aspects of model making.

\subsection{Creative thinking for idealizing solutions}

As analyzed by the author through various research papers, creative thinking should come under the umbrella of intuitive, visual, and simultaneous thinking during the design process which involves synthesizing, elaborating, and imagining. To predict the final solution to any design challenge, designers have to develop fluent responses to the issue and visualize and speculate their solutions based on the practical implications (Babangida Idi \& bin Mohamed Khaidzir, 2015). Besides this aspect, they also need to trust their judgment and decision to make the best solution as an outcome of the design process. Creativity does not only have an impact during the architectural learning in studios where they are educated to handle the design problem along with some real-world problems considered as a part of a studio project. In practice, designers also need to incorporate their creative expression improving with the design skills and knowledge from an ill-structured to define real structured design solution (Gann et al., 2003). It is also so evident that the ultimate aim of any architectural education must depend on the development of the creative personality where the knowledge and skills our primary focus on the expression of creativity and innovation in their design process. This aspect of design thinking should be fostered by encouraging the students during the learning process involved in brainstorming which can help one not only to get solutions for new challenges but also to decide which approach is the best suited to address the challenge (Heylighen \& Neuckermans, 2000). This can be further enhanced through discussions on individual concepts and interactions with peers which help them assessing the approach and refining it to suit the context. In real-time practice, the same fundamental is applied where the design decisions are taken in consultation with the client after their feedback and refinement during the iteration process before coming to the final output of the design (Abdellatif Abo Wardah \& Khalil, 2016).

\subsection{Visual representation of design activities}

As explained by Jones in Design Methods (1992, first edition in 1970), the design process does not necessarily explain the method of creativity, rather it is based on the principle of induction where the ultimate output is depicted through architectural representation and technical drawings (Abdellatif Abo Wardah \& Khalil, 2016). The significance of these presentations is primarily focused on three major operations that are gathering the data, testing, and assessment. 
It is most significant in terms of the design process at the cognitive level where it comprises of a series of an arrangement of design activities which are depicted as analysis-synthesisevaluation, seeing-moving-seeing for imaging-presenting and testing. This comprises of investigative approach where the concept is synthesized and the objectives and targets are being achieved through preliminary investigation, i.e., data collection, after the concept is finalized the created concept are then assessed with its defined set of objectives and then the final solution is synthesized to propose the desired output (S. A. Kim \& Y. S. Kim, 2007). During this phase of the design process, instead of taking a consecutive arrangement of the process, they are worked out in an iterative way where each solution is recognized investigated, and reexamined unless the final arrangement is approved. The cyclic process of iteration takes place distinctively amid the conceptual plan (Bashier, 2017). This is the phase where there is brainstorming of thoughts issues and imagination to examine the strategy and the exercise to discover important design solutions from verbal conventions and information protocol analysis is the process that has been applied on a broader level. Many a time, the verbal conventions are not adequate to clarify what is been worked out amid the plan (Mahmoodi, 2001). Sketching is the fundamental aspect of representation for creating and narrating the various arrangements which are conjointly reflected through recognizing conflicts and conceivable outcomes. In the previous researches, it has been identified that many designers depict their design solution from their sketches where this drawing gives a critical clue about his entire journey of evolution during the design process. Therefore, visual representation techniques give a vivid approach of portraying one's thoughts and activities with the strategies applied to reach the design solution.

\subsection{Design concepts generation stage}

The traditional planning approach of the generation of design concepts primarily dependent on verifiable knowledge and outlining the spatial arrangement by generating the threedimensional (3D) shapes. The method starts with articulation which is well composed and appears with the few design concept or thoughts as a distinctive approach which has risen from the developing integrated within the design processed by the designers. The evolution method is used for learning from the design experience of the past works where is inspiration is described as the most fundamental method of design generation amongst the architects. They often seek the insight termed as "inspiration" which is mostly derived from the work of other famous architects and then implementing the learning out of the project modifying their approach of design proposing the solution. In this regard, Heylighen and Neuckermans (2000) had proposed the concept of "cases" as the method of generation of concepts from the learning of previous projects. They have quoted their findings as "architects seems to draw a considerable amount of design knowledge from concrete design cases which are designed by others or by themselves" (Heylighen \& Neuckermans, 2000).

\subsection{Analysis and learning of conceptual design process}

As designers, architects are aware of the design brief and the design requirements of the project that they are dealing with. Since there is a variation in timings of any design task, the designers' work approach also varies accordingly. Where few designers follow the traditional approach 


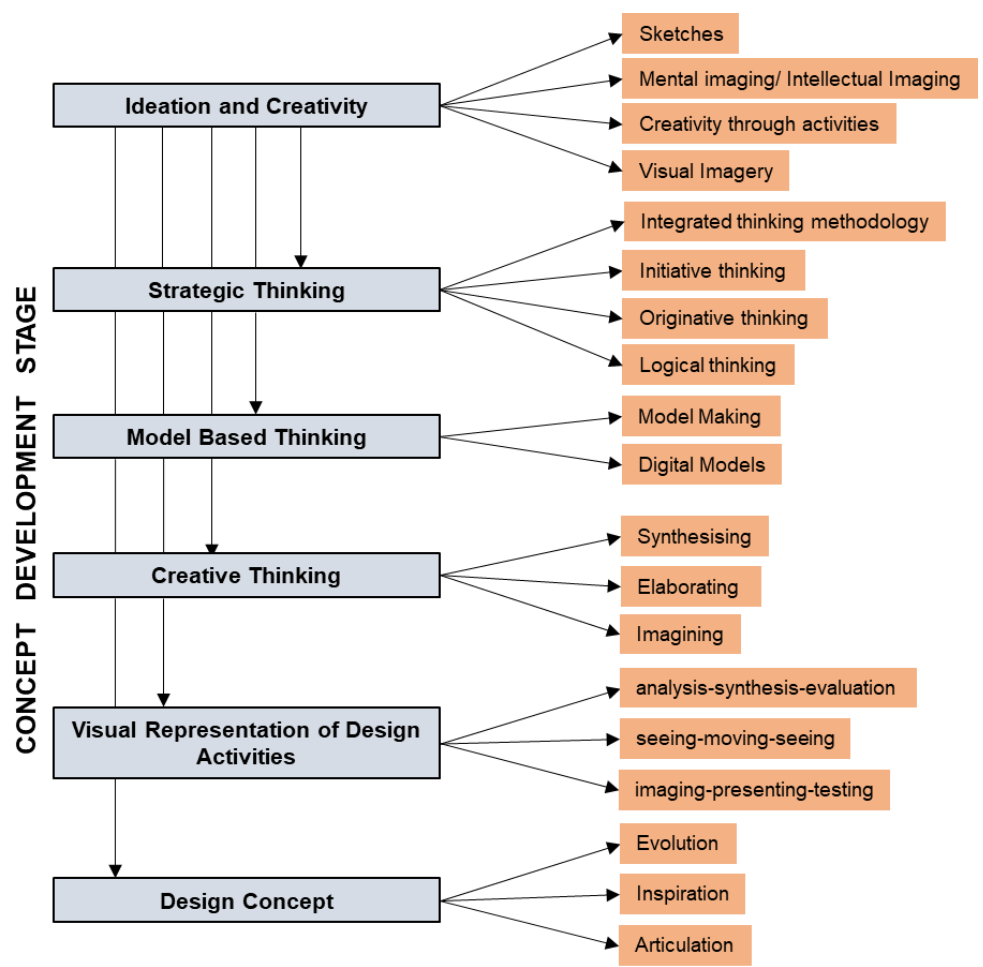

Figure 2. Stage 1: conceptual design process (source: created by author)

which inclusive of coordination, while others are not well versed with this concept (Prabhu et al., 2020). For them, knowledge and representation are their integral part of analyzing their design, and their success outline is based on justifying the reason behind the design decision. The various phases of the concept development stage are summarized below (Figure 2).

\section{Representation of design process}

The analysis of the relation of architecture and language encounters towards different forms of expressions. Firstly, the drawings and the models with the architect used to express their thoughts to the counter side whereas the other one is the final built form that reflects the design thought with its expression. These expressions of the design thinking process, which is termed as "representation language" are more often termed as the formal expression of formal language (Kuloglu \& Durmus, 2013). Representation is the essential tool of the architect with the user to establish their critical dialogue during the design process which is intimate wandering through one thought and in other words a tool to communicate the design features to other team members and the client. During this phase of the dialogue, choosing the appropriate method of representation majorly influences the outcome since the selection of the outcome inevitably enhances one solution over other alternative options setting to its priority. However, the most challenging aspect is how a designer can aspire to retrieve the status of presence to architecture (Kuloglu \& Durmus, 2013). 


\subsection{Expressing through storyboards and animatic}

To establish a preliminary overview of the narrative sequence, storyboards are the drawings produced for explaining the planned film scenes. Since it is a part of linear fast sketches, they are often termed similar to croquis in art and architecture. There are also defined as a mock of sequential seen permitting the to plan the views framing the size angle movement and the dialogue of various characters. In the case of animated storyboards, a change in the perception of the qualitative approach in line with the time and movement perceived imaginary actively in the traditional storyboards has now become explicit. The concept of the animatic approach, although it is sketchy, it stimulates rhythm within mounted sequences and transition of the film (Aroztegui et al., 2010). In addition to the sketches, the inclusion of the audio, time, and images with the variation of light and color allows an in-depth exploration of the ambiance of the atmosphere created for that particular place. This allows the designers to narrate their past experiences memories of the place and significant events of their lives when they narrate it through storyboards. As a result, the connectivity made with the places which they are familiar with creates a fusion of the designer with its context in an empathetic manner. The outcome of the resultant of this animatic illusion results in a persuasive account of living spaces where the designers realize the difference between the real-time experience of a particular place with the continuous visualization and filmic code of representation in the montage (Mahmoodi, 2001).

\subsection{Evolution of computer-aided design and building information modeling as a tool for representation}

Ivan Sutherland had developed a graphic interface technology which was termed Sketchpad which has enabled the designer to develop the virtual drawing depicting the design into digital more through a digital pen in the year 1963. CAD programs slowly started spreading from the next decade onwards. Although there has been a remarkable technology innovation approach which has been witnessed during this phase, CAD drawings were mostly the sophisticated two-dimensional (2D) tools to represent the design in 2D (Baptista Tavares Carreiro \& da Luz Pinto, 2013). To explore the three-dimensional model representation technique evolved during the end of 1980, which was termed as BIM, the major contribution of BIM was to integrate the comprehensive building information and represent the object in its virtual three dimensions from all the possible points and angle giving an overview of the model as followed by the Monge's method. By the use of such tools for representation, now it has been possible that architectural project is perceived in a more intricate and detailed way. The most significant example of information technology application of such a program is the distribution of air conditioning facility projects on a large-scale building where it is now possible to preview it in three dimensions considering the continuity of scale. It can also be viewed on the computer screen without any additional element which can interfere with it is their interpretation (Bashier, 2017). The research on the CAD programs in the next few years will merge with the computer-aided manufacturing and the numeric control which, as a result, shall include and new generative process integrating the variables and the algorithms 
to improve and enlarge the digital design and representation tools within a virtual reality environment and computer-aided three-dimensional interactive application (Baptista Tavares Carreiro \& da Luz Pinto, 2013).

\subsection{Virtual reality and immersive digital, interactive and augmented environments}

Mostly the architectural plans which are defined by the new geometry of spaces become a game of multiple relationships of spaces. Traditional representation systems of such designs are no longer satisfactory to communicate or translate the complexities which have been inherited in the design of such spaces. A major shift in the architectural representation in this domain is the evolution of virtual reality and immersive digital environment which has given the designer flexibilities for virtually experiencing the spaces in architecture. Access to this virtual reality technology not only and able for the development of the $3 \mathrm{D}$ visual representation of the design spaces but also the true intense experience in those spaces concerning materials fabric and interior ambiance unlike the aforementioned approximation techniques of reality such as collage, photomontage, or rendering, etc. In these spaces, it is imperative for the user to interfere with the space that surrounds him and therefore it gives the flexibility to the designer to play with its geometry alter it, change or reform it and rethink any possible moves that had been formerly thought (Irouke \& Ahianba, 2013). But in recent years another dimension has appeared in the interaction between the physical and the virtual: augmented reality and the old scientific-fiction - but more than ever true - hologram idea. A reality in the physical universe that is reinforced by its convergence with the virtual one and its reluctance to become anything other than what it is. Again, the physical/virtual boundary disappears and the two realities fall closer (Baptista Tavares Carreiro \& da Luz Pinto, 2013). The summary of the representation stage in the design process is shown in Figure 3.

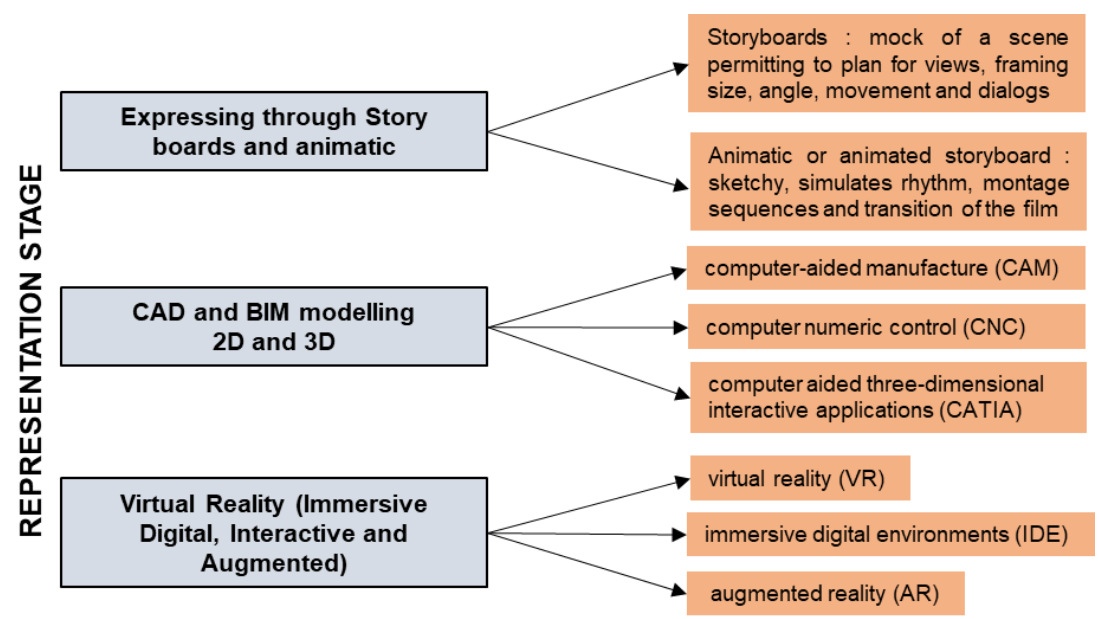

Figure 3. Stage 2: representation in design process (source: created by author) 


\section{Assessment of design process}

Design quality is challenging to place a quantitative score on since it includes both empirical and subjective aspects. The researcher is using user involvement and research evidence from recently implemented adaptable design evaluation and appraisal criteria, as well as literature and instructional lectures to summerise the assessment process in design. The various kinds of design characteristics may all be determined, and in the manner of the scale used, whether for the advantage of those who have given the design input or for the subjects, both lead to intangibles to some degree (Gann et al., 2003).

\subsection{Assessment of creativity and innovation}

In its widest possible sense, creativity is the age of novel and advanced technology is considered innovative and this to arrive at a successful solution. Creativity is a project and creativity a collaborative effort; the key distinction is that the projects include several different individuals working together, whereas collaborations include few individuals. Concerning the degree of ingenuity, the distinctions between innovation and creativity, the two terms are almost the same or even blurred. As far as finding new ways of doing things goes, it is ideation to the process of ideation is concerned, we might as well use the same formula as previously suggested by Edward de Bono: concept creation = idea generation (Burgh, 2014). The first step through the process of creativity is to define a particular challenge. This gives way to new ideas. The most valid way to measure imagination is when you report it to yourself. There were two different approaches to evaluating innovation: being quantitatively or qualitatively perceptive. Reports that evaluate a designer's abilities based on the judgment of others are similarly structured (termed as judgemental rating) to those based on self-reports (Bisadi et al., 2012). In recent researches, questionnaires have been used to determine the nature of imagination and invention as formulated by the researchers however, imagination is directly correlated with the amount of innovation one will be seen in the quantity of completed output, such as articles, software, algorithms, and patents.

\subsection{Design solution or hypothesis}

"Design solution" premises that a certain design outcome already exists. The exploratory "hypothesis" is focused on a transient trial-and-error method to potentially discover new product features or solutions. For other statistics, it is impossible to know whether or not a theory is true whether it is formed by the protocol, however, the use of additional evidence is still mandatory. Different architectures denote the need for different purposes, just as one would assume, such as optimality by procedural correctness (Taura \& Nagai, 2017).

\subsection{Understanding the views of users}

The challenge is finding out what people and communities users believe: diverse and often contradictory opinions might be present. Employees of one company might see one thing and clients another; same as in the other words, facilities management, customers, customers, support personnel, and caretakers might see various facets of the same venue. Closing 
the loop is needed for promoting user adoption of design involves expanding the range of definitions that users have and implementation. Designers must look at everything as an opportunity to better themselves and fine-tune their approaches while innovative product management and service package approaches are adopted. Several companies have faced requirements-related difficulties, but most of them have overcome them by articulating and structuring them into high-quality designs. This research in various industries reveals that users must possess knowledge regarding the types of outcomes that a design should be able to do and what it must do. Since users do not have the technical vocabulary that is preferred by many in the field, it is difficult for them to be heard, particularly while speaking with professionals (Ciepłucha, 2018).

\subsection{Design quality indicator tool for analyzing users' perspective}

In the course of designing the design quality indicator (DQI), the researcher focussed on strategies to evaluate new product launch interventions, measures to measure post-occupancy performance, and sustaining performance was invaluable to them. Other useful examples of expanding tools include:

- The post-occupancy review of building engineering: post-occupancy evaluation tool that provides commissioning clients, design and build teams, and the building's occupiers with useful snapshots of users' views and an assessment of technical and energy performance of a building;

- Building research establishment environmental assessment method (BREEAM), United Kingdom (UK) ecopoints, and sustainable project appraisal routine (SPeAR): both BREEAM and UK ecopoints systems provide measures of energy use in construction. An alternative tool is the SPeAR developed by consultants which provides a range of sustainability indicators to explore the total environmental contribution of a project (Jagtap, 2019).

\subsection{Simulation}

It is a comprehensive design phase. At this point, designs are produced in a scaled, proportionate, and accurate manner. Traditionally, designers are drawing up boards and scales with the aid of drawing up a comprehensive model. And when they doing so, they have little possibility of changing the big design choices. In this process, they developing the finished design and looking for the final modification. They begin to render graphics, such as viewpoints, in various parts of the architecture according to the client specifications. This process can be represented as a detailed drawing in AutoCAD and detailed modeling using 3D parameters of the same program. The common approach is to create $2 \mathrm{D}$ designs in all aspects, such as walls, columns, floors, curtains, steels, glasses, etc. in various layers in a single drawing. Then, to get the $3 \mathrm{D}$ articulation of the design, the architect uses the extrude parameter and renders it $3 \mathrm{D}$ and it is hard to modify more in the later phase. To achieve the detailed texture and color effects of the build, the detailed sketches made in the 3D form in AutoCAD must be converted to Autodesk 3ds Max. It can be created with the effect of the colors and textures of all materials. After this phase, improvements in the basic design diagram are almost difficult to foresee. This is the limitation in the practice of this form of method in the architectural 


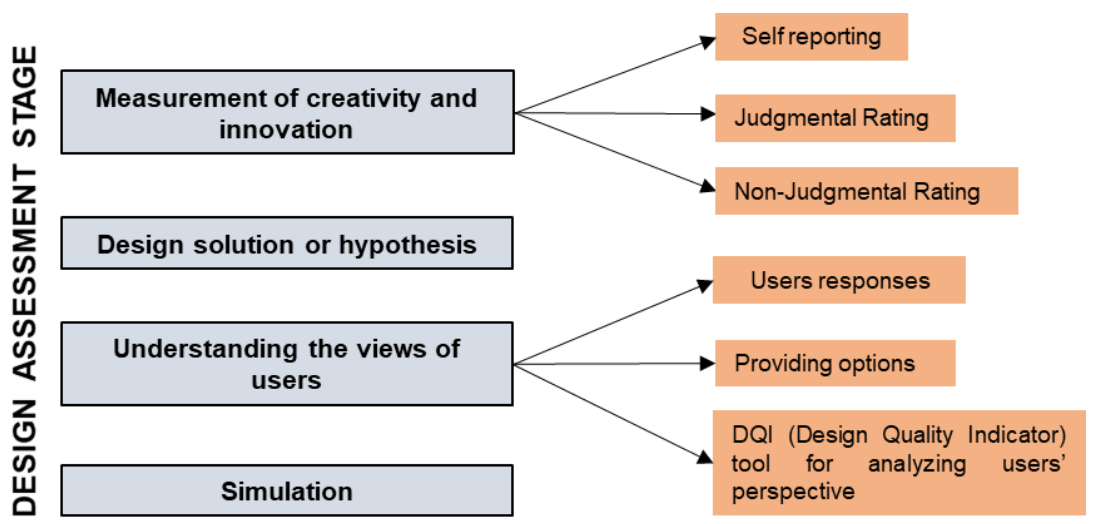

Figure 4. Stage 3: design assessment in design process (source: created by author)

design process (Siddique et al., 1990). In architecture, virtual or graphic modeling models may aid in the development of creative projects, taking into consideration a broad variety of parameters, such as structure, positioning, landscaping, and lighting. Realistic modeling may also be utilized to further create representations lifelike, creating value for customers. The 3DEXPERIENCE platform offers a streamlined way to construct and evaluate buildings utilizing different modeling software. The design assessment stage is summarised in Figure 4.

\section{Discussion}

Is architectural study deemed to be a means of furthering the advancement of the design process for architecture? To address this issue, the paper began by making a case for the fact that specific processes that had been addressed in various contexts starting from the 1980s till date which differ from one another. The designers learn even more about architecture design challenges and difficulties than they already imagined when they attempt to find the solution to it, which is why architectural design is very complicated. When performing the inquiry, architects use one or a combination of mechanisms that provide them with the details they need has been explained in more depth with regards to these methods, one of these mechanisms is the usage of concept exploration. While they are particularly hesitant to acknowledge it, architects are thought to learn a lot of their design work from prior ventures and were almost certainly either planned by or created by themselves. A project's research and design functions are invaluable assets in their own right but are often vital to its usage as places for experimenting and creating new knowledge. It tends to be more popular in architecture disciplines that creativity is triggered by operating on tangible programs, rather than working on abstract theories. Several people said they are involved in getting an edge over their rivals or seeking to obtain a personal benefit and benefit from their project designs. On the one side, it is possible to make a distinction between project design activities, which involve the project and which are driven by the project; but on the other, there is a more generalized mechanism that is linked to the analysis. More general than immediate goals, it 
may be: discovering the architectural principles of a particular site might be sought, looking at design possibilities of a certain venue, or researching an actual structural problem like dynamic balance is a typical aim. To achieve this aim, a clear understanding of the design process is a mandatory necessity. Since in literature there was no clear documentation of the sequencing of the design process, the researcher had attempted to identify and prioritize the various stages and support tools to define each stage. This shall enable future designers to critically re-think their design proposals before their execution on the site.

\section{Conclusions}

According to the theory of design, the design process should focus on reasonable knowledge is used to understand design, yet non-rational knowledge plays a distinct, but functioning role. The researcher had attempted to demonstrate three stages of addressing the design process through the available literature reviews. Indeterminate knowledge may be significantly reduced depending on the objective or subjective understanding of the architect's design challenge. The designer needs to undergo a clear distinct design process to propose his design solution logistically and rationally. Therefore, the study presented facts on previous research relevant to this issue, as shown by systematic analysis and a comprehensive review of the existing subject-related literature. The literature provides work on the design process as an information base that involves architectural conceptualization, representation, and assessment. The significance and the role of each stage defined by certain strategies have been summerized by the researcher. There always exists a strong inter-relationship between these three stages as the output is majorly influenced by the decision taken at each defined stage. To link the thought process of the designer with the client's requirements, there is a definite need for representation in terms of visual language and communication which enables the client to understand the technical know-how of the professional in its simplest way. The major design decisions need to be supported by the correct method of assessment as once it is finalized and brought for implementation on the site, it is difficult to do any major alternations thereafter. Since architecture is a field that is creative and innovative and has been always evolving with varied iterations, the techniques, and tools to address any design challenge to find its solution may also vary in a different context. However, further research could focus on re-defining these aspects considering various typologies of projects where, even though the strategies will remain the same but detailing of each type, may significantly vary with a varied range of projects, on which research can be further directed. There can be more updated tools and techniques of visual interpretation, that might have evolved, the documentation of which could be a scope of further research in this direction.

\section{References}

Abdellatif Abo Wardah, E. S., \& Khalil, M. O. (2016, 26-27 March). Design process and strategic thinking in architecture. In Proceedings of 2016 International Conference on Architecture and Civil Engineering (pp. 32-45). London, United Kingdom. URCAE.

Aroztegui, C., Solovyova, I., \& Nanda, U. (2010, 23-26 June). Architectural research and representation: expressing sense of place through storyboarding and animatics. In Proceedings of ARCC/EAAE 2010 
International Conference on Architectural Research. The European Association for Architectural Education/Architectural Research Centers Consortium. Washington, D.C., United States. https:// www.brikbase.org/sites/default/files/A012_Aroztegui.pdf

Ayyýldýz Potur, A., \& Barkul, Ö. (2006, 17-18 March). Creative thinking in architectural design education. In Proceedings of the 1st International CIB Endorsed METU Postgraduate Conference Built Environment and Information Technologies (pp. 113-125). Ankara, Turkey. Bursa Technical University.

Babangida Idi, D., \& Mohamed Khaidzir, bin K. A. (2015). Concept of creativity and innovation in architectural design process. International Journal of Innovation, Management and Technology, 6(1), 16-20. https://doi.org/10.7763/IJIMT.2015.V6.566

Baptista Tavares Carreiro, M., \& Luz Pinto, da P. (2013, 4-6 April). The evolution of representation in architecture. In Proceedings of Future Traditions: 1st eCAADe Regional International Workshop (pp. 27-38). Porto, Portugal. Association for Education and research in Computer Aided Architectural Design in Europe.

Bashier, F. (2017). Design process-system and methodology of design research. In IOP Conference Series: Materials Science and Engineering, 245(8). https://doi.org/10.1088/1757-899X/245/8/082030

Bisadi, M., Mozaffar, F., \& Bahger Hosseini, S. (2012). Future research centers: the place of creativity and innovation. Procedia - Social and Behavioral Sciences, 68, 232-243.

https://doi.org/10.1016/j.sbspro.2012.12.223

Burgh, G. (2014). Creative and lateral thinking: Edward de Bono. In D. C. Phillips (Ed.), Encyclopedia of Educational Theory, Vol. 1 (pp. 187-188). SAGE Publications, Inc.

Ciepłucha, W. (2018). 7 design methods in architecture. In A. Mielnik (Ed.), Defining the architectural space: rationalistic or intuitive way to architecture, Vol. 8 (pp. 13-22). Naukowe PWN.

Cross, N. (2001). Designerly ways of knowing: design discipline versus design science. Design Issues, 17(3), 49-55. https://doi.org/10.1162/074793601750357196

Cross, N. (2007). From a design science to a design discipline: understanding designerly ways of knowing and thinking. In R. Michel (Ed.), Board of International Research in Design. Design research now: essays and selected projects (pp. 41-54). Birkhäuser Verlag AG. https://doi.org/10.1007/978-3-7643-8472-2_3

Daniel, R. (2021). Exploring creativity through artists' reflections. Creativity Studies, 14(1), 1-17. https://doi.org/10.3846/cs.2021.11207

Discoverdesign. (2012-2019). Discover design: Chicago architecture center. https://discoverdesign.org/

Editorial Board of International Journal of Design Creativity and Innovation. (2013). Perspectives on design creativity and innovation research. In T. Taura \& Y. Nagai (Eds.), International Journal of Design Creativity and Innovation, 1(1), 1-42. https://doi.org/10.1080/21650349.2013.754657

Gann, D. M., Salter, A. J., \& Whyte, J. K. (2003). Design quality indicator as a tool for thinking. Building Research and Information, 31(5), 318-333. https://doi.org/10.1080/0961321032000107564

Gohardani, N. (2011). Architecture and design research: reflections in relation to the design process. International Journal of Architectural Research, 5(3), 107-115.

Heylighen, A., \& Neuckermans, H. (2000, 4-8 July). Design(ing) knowledge in architecture. In Proceedings of European Association for Architectural Education/Architectural Research Centers Consortium Conference 2000. Paris, Lyon, France. https://www.researchgate.net/publication/239734680_Designing_knowledge_in_architecture

Irouke, V. M., \& Ahianba, J. E. (2013). Advancement of creativity in architectural design education. Journal of Environmental Studies, 1(1), 78-82.

Jagtap, S. (2019). Design creativity: refined method for novelty assessment. International Journal of Design Creativity and Innovation, 7(1-2), 99-115. https://doi.org/10.1080/21650349.2018.1463176

Jones, J. Ch. (1992). Design methods. John Wiley \& Sons, Inc. 
Kim, S. A., \& Kim, Y. S. (2007, 28-31 July). Design process visualizing and review system with architectural concept design ontology. In DS 42: Proceedings of ICED 2007, the 16th International Conference on Engineering Design, Paris, France. https://www.designsociety.org/publication/25612/Des ign+Process+Visualizing+and+Review+System+With+Architectural+Concept+Design+Ontology

Kuloglu, N., \& Durmus, S. (2013). Architecture and technology: architect's expression language in design process. In ATINER's Conference Paper Series No. ARC2013-0701. Athens Institute for Education and Research. https://www.academia.edu/15464141/Architecture_and_Technology_ Architect_s_Expression_Language_in_Design_Process

Mahmoodi, A. S. M. (2001). The design process in architecture: a pedagogic approach using interactive thinking [PhD/Doctor Thesis, University of Leeds]. Leeds, United Kingdom. https://etheses.whiterose.ac.uk/2155/1/uk_bl_ethos_543080.pdf

Mahmoud, N. E., Kamel, Sh. M., \& Hamza, T. S. (2020). The relationship between tolerance of ambiguity and creativity in architectural design studio. Creativity Studies, 13(1), 179-198. https://doi.org/10.3846/cs.2020.9628

Prabhu, R., Bracken, J., Armstrong, C. B., Jablokow, K., Simpson, T. W., \& Meisel, N. A. (2020). Additive creativity: investigating the use of design for additive manufacturing to encourage creativity in the engineering design industry. International Journal of Design Creativity and Innovation, 8(4), 198-222. https://doi.org/10.1080/21650349.2020.1813633

Pryshchenko, S. V. (2021). Cultural heritage of a poster: communicative and creative experience. Creativity Studies, 14(1), 18-33. https://doi.org/10.3846/cs.2021.12605

Siddique, M. N. H., Mowla, Q. A., \& Masum, al M. A. (1990). Virtuality in architecture: a design metaphor. In Project: Architectural Pedagogy for the Contemporary Context (pp. 342-350). Bangladesh University of Engineering and Technology.

Taura, T., \& Nagai, Y. (2017). Creativity in innovation design: the roles of intuition, synthesis, and hypothesis. International Journal of Design Creativity and Innovation, 5(3-4), 131-148. https://doi.org/10.1080/21650349.2017.1313132 